\title{
Hyperthermia depletes Oct4 in mouse blastocysts and stem cells
}

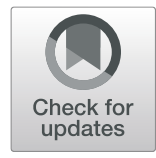

\author{
Mo-bin Cheng ${ }^{1 \dagger}$, Xue Wang $^{2+}$, Yue Huang ${ }^{2^{*}}$ and Ye Zhang ${ }^{1 *}$ (D)
}

\begin{abstract}
Temperature is an important microenvironmental factor that functions epigenetically in normal embryonic development. However, the effect of hyperthermia in the stem cells is not fully understood. Oct4 is a tightly regulated master regulator of pluripotency maintenance in stem cells and during early embryonic development. We report here that Oct4 protein level was significantly reduced under hyperthermia in mouse blastocysts and embryonic stem cells. The reduction in Oct4 in the mouse embryonic stem cells under hyperthermia was mediated by a ubiquitin-proteasome pathway that was dependent on the activity of death-associated protein kinase 1 (Dapk1) to phosphorylate its substrate, Pin1. Our results imply that the depletion of Oct4 via brief hyperthermia, such as a high fever, during early pregnancy might severely impair the growth of the mammalian embryo or even cause its death.
\end{abstract}

Keywords: Hyperthermia, Oct4, Pin1, Blastocyst, Embryonic stem cells

\section{Background}

Oct4 is a master transcriptional regulator that maintains the naive pluripotency of stem cells. A deficiency in Oct4 fails to form a pluripotent inner cell mass (ICM) that results in the pre-implantation lethality of the mouse embryo [1]. Oct4 is capable of reprogramming various somatic cell types into pluripotent cells, either in combination with other transcription factors [2] or on its own [3]. The maintenance of an appropriate level of Oct4 in stem cells leads to either the maintenance of pluripotency or cell lineage differentiation $[4,5]$.

An appropriate temperature is known to be a microenvironmental or epigenetic factor in normal embryonic development in the animal kingdom; in contrast, hyperthermia is an established teratogen in mammals, including humans [6]. However, we know next to nothing regarding

\footnotetext{
* Correspondence: huangyue@pumc.edu.cn; yezhang@ibms.pumc.edu.cn ${ }^{+}$Mo-bin Cheng and Xue Wang contributed equally to this work.

${ }^{2}$ State Key Laboratory of Medical Molecular Biology, Department of Medical Genetics, Institute of Basic Medical Sciences, Chinese Academy of Medical Sciences \& Peking Union Medical College, Beijing 100005, China 'State Key Laboratory of Medical Molecular Biology, Department of Biochemistry and Molecular Biology, Institute of Basic Medical Sciences, Chinese Academy of Medical Sciences \& Peking Union Medical College, 5 Dongdan Santiao, Beijing 100005, China
}

the effect and mechanism of hyperthermia on stem cells or embryonic development.

Here, we report hyperthermia induces depletion of Oct4 in mouse blastocysts and stem cells, which is mediated by a ubiquitin-proteasome pathway that is dependent on hyperthermia activated Dapk1/Pin1 pathway.

\section{Methods \\ Cell lines and cell culture}

Mouse E14 ESCs were cultured in KnockOut DMEM (Life Technologies, Grand Island, NY) supplemented with 15\% FCS (Sigma, St. Louis, MO), 1× GlutaMAX (Gibco, Grand Island, NY), 1× PEN/STREP (Millipore, Philadelphia, PA), $20 \mu \mathrm{M} \beta$-mercaptoethanol (Millipore), $1 \%$ nonessential amino acids (Millipore), $1 \%$ nucleotide mix (Millipore), and $100 \mathrm{U} / \mathrm{ml}$ Leukemia inhibitory factor (LIF, Millipore) on gelatinized tissue culture plates at a density of $2.5-5 \times 10^{4} / \mathrm{cm}^{2}$. Mouse JM8A3 ESCs (kindly provided by Dr. Allan Bradley) were cultured in a maintenance medium consisting of KnockOut DMEM supplemented with 15\% KnockOut Serum Replacer (Life Technologies, $0.1 \mathrm{mM} \beta$-mercaptoethanol, $0.1 \mathrm{mM}$ nonessential amino acids, $1 \mathrm{mM}$ glutamine, and $1000 \mathrm{U} / \mathrm{ml}$

(c) The Author(s). 2020 Open Access This article is licensed under a Creative Commons Attribution 4.0 International License, which permits use, sharing, adaptation, distribution and reproduction in any medium or format, as long as you give appropriate credit to the original author(s) and the source, provide a link to the Creative Commons licence, and indicate if changes were made. The images or other third party material in this article are included in the article's Creative Commons licence, unless indicated otherwise in a credit line to the material. If material is not included in the article's Creative Commons licence and your intended use is not permitted by statutory regulation or exceeds the permitted use, you will need to obtain permission directly from the copyright holder. To view a copy of this licence, visit http://creativecommons.org/licenses/by/4.0/ The Creative Commons Public Domain Dedication waiver (http://creativecommons.org/publicdomain/zero/1.0/) applies to the data made available in this article, unless otherwise stated in a credit line to the data. 
LIF). HEK293T (no. 3111C0001CCC000091) and P19 (no. 3111C0001CCC000020) cell lines were purchased from Chinese National Infrastructure of Cell Line Resource. HEK293T cells were maintained in RPMI 1640 supplemented with $10 \%$ fetal calf serum. P19 embryonic carcinoma cells were maintained in $\alpha$-MEM supplemented with $10 \%$ fetal calf serum.

\section{Antibodies and plasmids}

Antibodies against Oct4, Lamin B, and GAPDH were purchased from Santa Cruz Biotech (Santa Cruz, CA). Sox2, c-Myc, Pin1, and Dapk1 antibodies were purchased from Abgent Biotech (San Diego, CA). Klf4 and Lin28 antibodies were purchased from Cell Signaling Technology, Inc. (Danvers, MA). FLAG FLAG-tagged and HA HAtagged antibodies were purchased from Sigma.

The FLAG-tagged Pin1 and HA-tagged Pin1 eukaryotic expression plasmids were constructed by cloning Pin1 CDS into pCDNA6-FLAG and pCDNA6HA vectors, respectively, using a PCR product amplified from a mouse ESC cDNA library. Specific primers (forward, GGGGTACCATGGCGGACGAGGAGAAG; reverse, CGGGATCCTCATTCTGTGCGCAGGAT) were used for the PCR amplification. We created a point mutation in amino acid 73 ( $\mathrm{S}$ to $\mathrm{A}$ ) in full-length FLAGPin1 or HA-Pin1. Specific primers (forward, TCACGG CGGCCCGCGTCCTGGCGGCAG; reverse, CTGCCG CCAGGACGCGGGCCGCCGTGA) were used for the PCR amplification. The FLAG/GFP-tagged Oct4 eukaryotic expression plasmid was a gift from Dr. Wenji Dong of Peking Union Medical College. The HAUbiquitin (Ub) eukaryotic expression plasmid was a gift from Dr. Linfang Wang of Peking Union Medical College. The oligonucleotide sequences of the Dapk1 small hairpin RNA (shRNA) were designed using Block-iT RNAi Designer (GGACACCTCCATTACTCATTGT, Life Technologies) and were connected with a HindIII/ BamHI pRS vector.

\section{Mouse blastocyst collection and immunofluorescence}

All mouse experimental protocols were approved by the Institutional Animal Care and Use Committee at Peking Union Medical College and Chinese Academy of Medical Sciences. Female mice (C67BL/6 N) were superovulated by injections of pregnant mare serum gonadotropin and human chorionic gonadotropin. The superovulated females were mated with male mice (B6D2F1), and the E3.5 blastocysts were flushed out of the uterus.

The immunofluorescence analysis of the blastocysts was performed as previously described [7], with minor modifications. Briefly, the blastocysts were placed in a drop of M16 medium under mineral oil and were incubated at $37^{\circ} \mathrm{C}, 39^{\circ} \mathrm{C}$, and $42^{\circ} \mathrm{C}$ in a humidified atmosphere containing $5 \% \mathrm{CO}_{2}$. The blastocysts were fixed with $4 \%$ paraformaldehyde for $20 \mathrm{~min}$ at room temperature (RT). After being washed with PBS, the blastocysts were permeabilized with $0.5 \%$ Triton X-100 for $10 \mathrm{~min}$ and were then incubated in blocking solution $(0.2 \% \mathrm{BSA})$ for $30 \mathrm{~min}$. The blastocysts were incubated with a primary antibody overnight at $4{ }^{\circ} \mathrm{C}$, washed three times with $0.01 \%$ Triton X-100, and then incubated in a blocking solution containing a secondary antibody for 1 $\mathrm{h}$ at RT. After being washed three times with $0.01 \%$ Triton X-100, the blastocysts were mounted on glass slides with DAPI. Images were obtained using an OLYMPUS FV1000 confocal microscope. Antibodies were used for immunofluorescence of Nanog (AB5731, Millipore) and Klf4 (sc-20691, Santa Cruz).

We collected Dapk1 $1^{-1-}$ embryos via a two-step procedure: (1) generated Dapk $1^{+/-}$mice by crossing Dapk1flox/+ mice with EIIa-cre transgenic mice [strain name: FVB/N-Tg (EIIa-cre) C5379Lmgd/J); Dapk1 ${ }^{\text {flox/+ }}$ mice, in which the exon3 of one Dapk1 allele was flanked by two loxP sites, were kindly provided by Prof. Youming $\mathrm{Lu}$ (Huazhong University of Science and Technology, Wuhan)]. (2) Female Dapk $1^{+/-}$mice were superovulated by treating them with pregnant mare serum gonadotropinis (Sansheng Biological Technology) and human chorionic gonadotropin, then were crossed with male Dapk1 $^{+/-}$mice. The blastocysts were flushed out of the uterus at E3.5.

\section{Immunoprecipitation (IP) and immunoblot analyses}

Co-IP analyses were performed with $\sim 500 \mu \mathrm{g}$ of proteins incubated with specific antibodies for $2 \mathrm{~h}$ at $4{ }^{\circ} \mathrm{C}$. Next, $20 \mathrm{ml}$ of Protein A (or G)-agarose was added and incubated at $4{ }^{\circ} \mathrm{C}$ overnight. The pellets were then washed with RIPA buffer, $40 \mu$ of $1 \times$ Laemmli buffer was added, and then, they were suspended and boiled. The samples were separated by SDS-PAGE and were sequentially analyzed by Western blotting with individual antibodies. For quantification of Western blots, the membranes were scanned for analysis of the relative level of protein expression. The intensity of each protein band was determined by densitometry and divided by GAPDH gray value for normalization.

\section{Colony formation assays}

The JM83A ESCs were suspended in culture medium after trypsinization and treated with a $37^{\circ} \mathrm{C}$ or $42^{\circ} \mathrm{C}$ water bath for 1,3 , or $6 \mathrm{~h}$. Subsequently, and then 1000 cells were seeded on one well of six-well plate (100 cells/ $\mathrm{cm}^{2}$ ). After $8 \mathrm{~d}$ culture, the ESC colonies were stained with methylene blue (1\% in $75 \%$ ethanol) for $15 \mathrm{~min}$, followed with washing with $75 \%$ ethanol for $1 \mathrm{~min}$. 


\section{Quantitative real-time RT-PCR (RT-qPCR)}

RT-qPCR was performed as previously described. The relative expression levels of the Oct4, Nanog, Sox2, and Klf4 genes were normalized against GAPDH using the comparative CT method, according to the manufacturer's instructions (Roter-Gene RG-3000A Real-Time PCR System, Corbett Research, Australia). The primer sequences used are as follows: for Oct4 (Pou5f1), forward, 5'TCACTCACATCGCCAATCA3', reverse, 5' GTAGCCTCATACTCTTCTCGTT3'; Nanog, forward, 5' AGGACAGGTTTCAGAAGCAGA3', reverse, 5' CCATTGCTAGTCTTCAACCACTG3'; Sox2, forward, 5'GCAGTACAACTCCATGACC3', reverse, 5'CCTC GGACTTGACCACAGA3'; Klf4, forward, 5'CACACTT GTGACTATGCAG3', reverse, 5'AGTGCCTGGTCAGTTCATC3'; and GAPDH, forward, 5'GCACAGTCAAGGCCGAGAAT3', reverse, 5'GCCTTCTCCATG GTG GTGAA3'. The experiments were repeated at least three times. All the data from the experiments are expressed as the means $\pm \mathrm{SD}$.

\section{Ubiquitination assay}

The mESCs were transfected with combinations of plasmids, including HA-ubiquitination (HA-Ub). After incubation for $42 \mathrm{~h}$, the cells were treated with MG132 (25 $\mathrm{mM}$ ) for $6 \mathrm{~h}$. Whole cell extracts (WCEs) were immunoprecipitated with an antibody against Oct4 and were blotted with an antibody against HA. The HEK293T cells were co-transfected with combinations of plasmids, including HA-ubiquitination (HA-Ub) and FLAG/GFPOct4. After incubation for $42 \mathrm{~h}$, the cells were treated with MG132 (25 mM) for $6 \mathrm{~h}$. The WCEs were immunoprecipitated with an antibody against FLAG or GFP and were blotted with an antibody against HA.

\section{Statistical analysis}

Statistical analysis was performed using two-tailed Student's $t$ test. All data are shown as the mean with standard deviations (SD) from at least three independent experiments. Probabilities of $P \leq 0.05$ were considered as significant $(*)$ and $P \leq 0.01$ as highly significant ${ }^{(* *)}$.

\section{Results and discussion}

\section{Hyperthermia depletes Oct4 in mouse blastocysts and} stem cells

Because the maintenance of a pluripotent ICM is Oct4 dependent and the ICM is more sensitive to elevated temperatures in the blastocyst than in the trophectoderm [8], we thus determined the expression levels of the pluripotency-associated transcription factors such as Oct4 in the ICM after hyperthermia. Mouse blastocysts were pretreated at 39 or $42^{\circ} \mathrm{C}$ for $1 \mathrm{~h}$, and the expression levels of the transcription factors were then detected by immunofluorescence staining. We showed that although the Oct4 level in the ICM diminished significantly after $42{ }^{\circ} \mathrm{C}$ treatment, Klf4 and Sox 2 remained largely unchanged. Nanog was reduced compared with the control after treatment at $37^{\circ} \mathrm{C}$ (Fig. 1a). These results indicated that hyperthermia produces the largest significant decrease of Oct 4 expression during early embryonic development.

Next, we investigated the effects of hyperthermia on the expression of the key pluripotency transcription factors in embryonic stem cells (ESCs). We showed in mouse ESCs (E14) that the Oct4 protein expression was remarkably reduced under hyperthermia $\left(42^{\circ} \mathrm{C}\right.$ for $\left.1 \mathrm{~h}\right)$, and western blotting showed a full recovery $6 \mathrm{~h}$ after the removal of the cells from the stress. Similar results were demonstrated for Nanog, albeit to a lesser extent (Fig. 1b, left panel and Fig. 1c, upper panel). A similar profile was also shown in the JM83A mouse ESCs (Fig. 1b, right panel and Fig. 1c, lower panel). In contrast to Oct4 and Nanog, other important pluripotency factors, such as Sox2, Klf4, c-Myc, and Lin 28, were not affected at the protein level by hyperthermia. We then treated P19 cells (mouse embryonic carcinoma cells) with a series of temperatures from 38 to $42{ }^{\circ} \mathrm{C}$ to verify that an Oct4 reduction could be caused by temperatures elevated to the fever range. The results demonstrated that Oct4 and Nanog were reduced in the P19 cells only at $40^{\circ} \mathrm{C}$ or higher (Fig. 1d and e). HEK293T cells transfected with FLAG-tagged Oct4 were further subjected to heat treatment, and the thermal-dependent reduction of ectopic FLAG-tagged Oct 4 was clearly identified by antibodies against either Oct4 or its FLAG-tag (Fig. If and g). To assess the impact of hyperthermia on the self-renewal of mouse ESCs (mESCs), a colony formation assay was performed. It was shown that colony formation was severely impaired by hyperthermia at $42^{\circ} \mathrm{C}$ (Fig. 1h). We thus suggest that the hyperthermia-mediated reduction in Oct4 is associated with the inhibition of self-renewal in mESCs.

\section{Thermal degradation of Oct4 is Dapk1/Pin1 pathway dependent}

To determine how the Oct4 reduction is regulated under hyperthermia, we first demonstrated that the mRNA levels of Oct4, Nanog, Sox2, and Klf4 in E14 mESCs were not obviously affected under hyperthermia using real-time RT-PCR (Fig. 1i) and RNA-Seq (data not shown). In contrast, the proteasome inhibitor MG132 could prevent the Oct4 reduction under hyperthermia in E14 mESCs (Fig. 2a), suggesting that the rapid degradation of Oct4 is proteasome dependent. In addition, the presence of MG132 significantly induced the accumulation of polyubiquitinated Oct4 under hyperthermia in mESCs (Fig. 2b). We thus confirm that the degradation of Oct4 is mediated by a ubiquitin-proteasome pathway. 

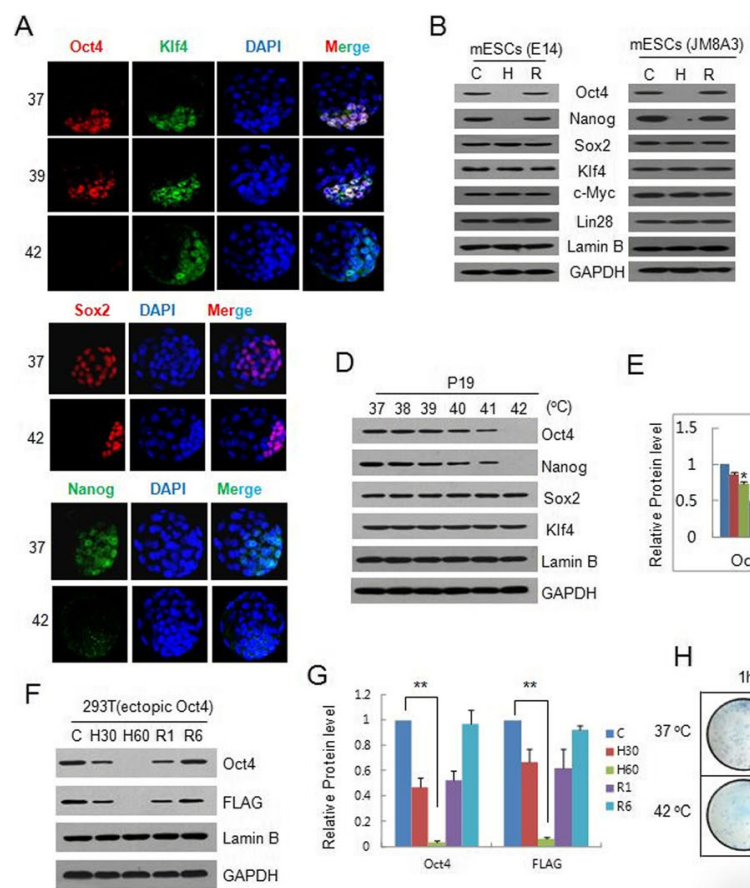

$\mathrm{E}$
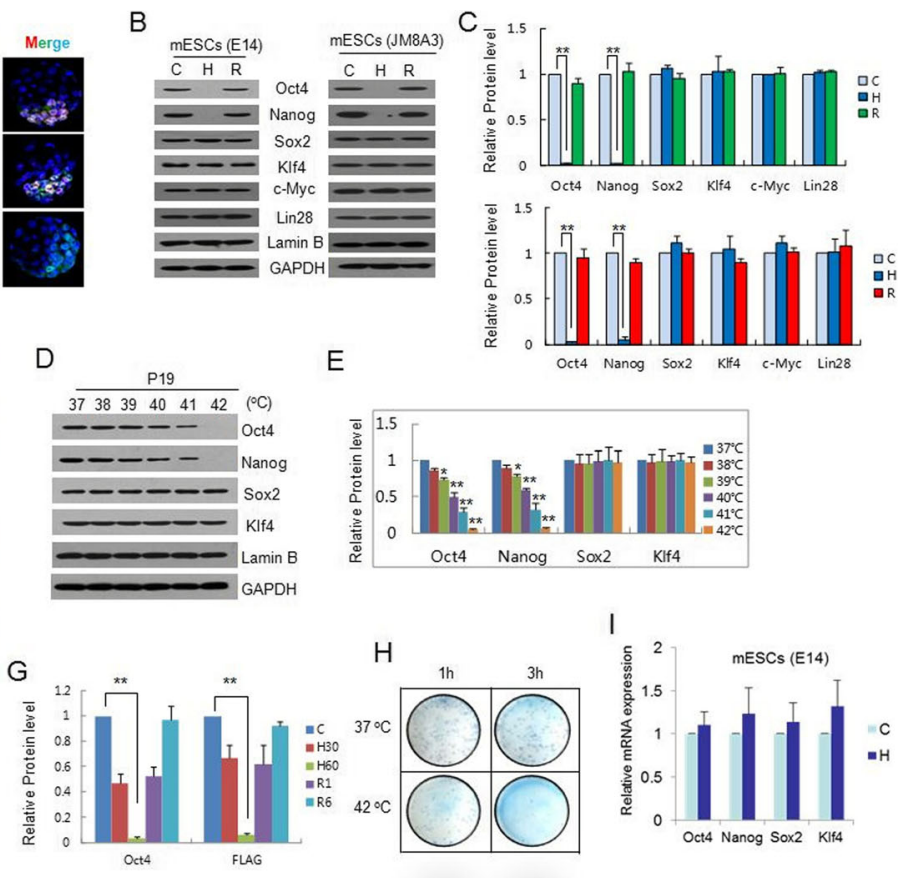

Fig. 1 Impact of hyperthermia on Oct4 expression in mouse blastocysts and ESCs. a Immunostaining of Oct4, KIf4, Sox2, and Nanog in the ICMs of E3.5 blastocysts. The blastocysts were incubated for $1 \mathrm{~h}$ at the indicated temperature, and the nuclei were shown by DAPI staining (blue). $\mathbf{b}, \mathbf{c}$ Western blot analysis of Oct4, Nanog, Sox2, Klf4, c-Myc, and Lin28 from E14 and JM83A mESCs. Lamin B and GAPDH were used as controls. C, $37^{\circ} \mathrm{C} ; \mathrm{H}, 42^{\circ} \mathrm{C}$ for $1 \mathrm{~h}$; $\mathrm{R}$, recovery at $37^{\circ} \mathrm{C}$ for $6 \mathrm{~h}$ following $42^{\circ} \mathrm{C}$ treatment $(\mathbf{b})$. Quantification data represent the mean $\pm S D$ of three independent experiments. $* p<0.05, * * p<0.01$ (c). d, e Western blot analysis of Oct4, Nanog, Sox2, and KIf4 from P19 cells incubated for $1 \mathrm{~h}$ at each indicated temperature (d). Quantification data represent the mean \pm SD of three independent experiments. $* p<0.05, * * p<0.01$ (e). $\mathbf{f}, \mathbf{g}$ Western blot analysis of ectopically expressed FLAG-tagged Oct4 from HEK293T cells (f). Quantification data represent the mean \pm SD of three independent experiments. $* p<0.05, * * p<0.01$ (g). $\mathbf{h}$ Colony formation assays of JM8A3 mESCs treated as indicated. The colonies were visualized using methylene blue staining. i Hyperthermia produced no obvious effects on the mRNA expression of oct4, nanog, sox2, or klf4 in E14 mESCs, as revealed by real-time RT-PCR assays. Each bar represents the mean value obtained from at least three independent experiments normalized against gapdh mRNA; the S.D. is shown on top of each bar

To explore the mechanism of the thermal degradation of Oct4, the death-associated protein kinase 1 (Dapk1)/ Pin1 pathway was determined. Pin1 is a prolyl cis/trans isomerase that functions to regulate the stability of its substrates via phosphorylation-dependent ubiquitinationmediated degradation [9]. Pin1 is indispensable for the self-renewal and maintenance of pluripotent stem cells [10]. Dapk1 phosphorylates human Pin1 at Ser71 (mouse Ser73), which is a catalytic site that inactivates Pin1 isomerase activity [11]. We demonstrated that during hyperthermia, the level of phosphorylated Pin1 gradually increased, which is in accordance with the accumulation of Dapk1, whereas there was no obvious change in the level of Pin1 in E14 mESCs (Fig. 2c). In contrast, the hyperthermia-induced phosphorylation of Pin1 was prevented by the knockdown of Dapk1, which protected Oct4 from degradation. However, the interaction between Pin1 and Oct4 remained unchanged (Fig. 2d). We next cloned an expression construct of mouse Pin1 with an S73A mutation and found that the non-effective S73 phosphorylation site in the Pin1 mutant could again prevent Oct4 degradation under hyperthermia (Fig. 2e). We also showed that either the knock down of Dapk1 (iDapk1) or the mutation of the Pin1 phosphorylation site abolished the accumulation of polyubiquitinated ectopic Oct4 (Fig. $2 \mathrm{f}$ and g). These results indicated that phosphorylation interfered with the prolyl isomerase activity of Pin1 on stabilizing Oct4, which was thus degraded via a ubiquitin/proteasome pathway. We suggested that Dapk1 abrogate stem cell maintenance and embryonic development via its phosphorylation of the Pin1-S73, which promote the degradation of Oct4 under hyperthermia.

To explore whether DAPK1 regulates Oct4 expression in hyperthermia condition during embryonic development, we detected the expression of Oct4 in Dapk $1^{-1-}$ blastocysts upon hyperthermia at $42{ }^{\circ} \mathrm{C}$ for $1 \mathrm{~h}$. We collected Dapk1 ${ }^{-1-}$ embryos via a two-step procedure as described in experimental procedures. To distinguish the DAPK1-null embryos from the others with different genotypes by using DAPK1 immunofluorescence, we tried several times but failed, which most likely due to lack of enough blastocysts. 

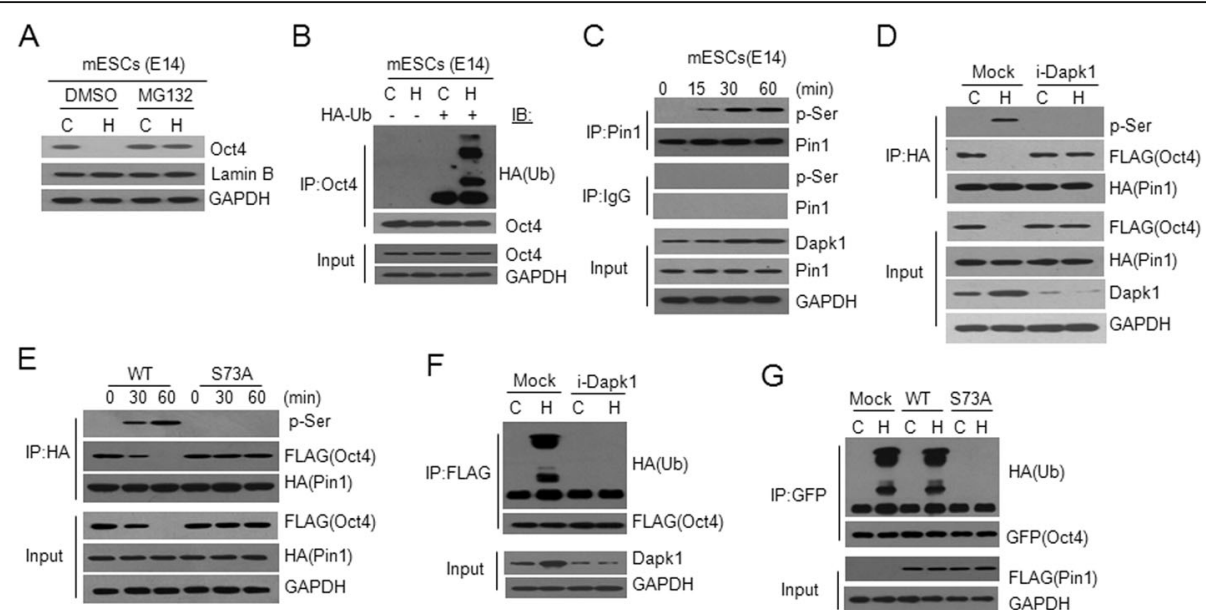

Fig. 2 The hyperthermia-promoted degradation of Oct4 mediated by Dapk1/Pin1-dependent ubiquitin-proteasome pathway. a MG132 prevented the degradation of Oct4. $\mathbf{b}$ Hyperthermia induced the accumulation of ubiquitinated Oct4 in the presence of MG132. Whole cell extracts (WCEs) were immunoprecipitated (IP) with anti-Oct4 and were blotted (IB) with anti-HA and anti-Oct4. c Hyperthermia facilitated the phosphorylation of Pin 1 in E14 mESCs. IP extracts of Pin1 and IgG (negative control) were blotted with antibodies against pan-phosphorylated serine (p-Ser) and Pin1. The inputs were blotted with antibodies against Dapk1, Pin1, and GAPDH. $\mathbf{d}$ Knockdown of Dapk1 abrogated both the phosphorylation of Pin1 and the degradation of Oct4 in HEK293T cells ectopically expressing FLAG-Oct4 and HA-Pin1. WCEs were immunoprecipitated with anti-HA and blotted with the antibodies indicated on the right. e A Pin1-S73A mutant blocked the hyperthermia-mediated degradation of Oct4. HEK293T cells transfected with FLAG-Oct4 and either HA-tagged Pin1 (WT) or mutant Pin1 (S73A) were treated for the indicated minutes (min). f Knockdown of Dapk1 prevented the ubiquitination of Oct4 in cells ectopically expressing FLAG-Oct4 and HA-Ub. g A Pin1-S73A mutant prevented the ubiquitination of Oct4 in HEK293T cells ectopically expressing GFP-Oct4 and HA-Ub

In fact, hyperthermia has been used for cancer therapy for more than a century. Numerous clinical and basic studies have shown that hyperthermia can significantly alter tumor cell survival [12]. However, we provide the first evidence on the changes in stem cells under hyperthermia conditions, which suggest, similar to a high fever, hyperthermia could severely impair the growth of a mammalian embryo in early pregnancy or even cause its death. Whether the reduction in Nanog in certain cell types is secondary to the depletion of Oct4 under hyperthermia or whether Nanog is degraded via a similar or alternate mechanism is an interesting topic remained to be explored.

\section{Conclusion}

In summary, hyperthermia could promote the degradation of Oct4 in mouse ICM, ESCs, and P19 cells. S73phosphorylation blocked the prolyl cis/trans isomerase activity of Pin1, thereby destabilizing Oct 4 for ubiquitinproteasome-mediated degradation. These hyperthermiainduced changes impaired the renewal of stem cells during early embryogenesis.

\section{Abbreviations}

DAPK: Death-associated protein kinase; ESC: Embryonic stem cell;

IP: Immunoprecipitation; ICM: Inner cell mass; RT-qPCR: Quantitative real-time RT-PCR

\section{Acknowledgements}

We thank Dr. W Dong and L Wang for kindly providing plasmids. We thank Dr. Y Lu (Huazhong University of Science and Technology, Wuhan) for kindly providing Dapk $1^{\text {flox/+ }}$ mice.

\section{Authors' contributions}

$M C$ carried out the molecular studies and drafted the manuscript. XW carried out the immunoassays of mouse blastocysts. $\mathrm{YH}$ and $\mathrm{YZ}$ conceived of the study, participated in its design, and wrote the manuscript. The authors read and approved the final manuscript.

\section{Funding}

This work was supported by the CAMS Initiative for Innovative Medicine (2016-I2M-3-002, 2017-I2M-3-009) and the National Natural Science Foundation of China (91519301, 31871310).

\section{Availability of data and materials}

The authors confirm that all data underlying the findings are fully available.

Ethics approval and consent to participate

This study was approved by The Ethics Committee of the Institute of Basic Medical Sciences, Chinese Academy of Medical Sciences.

Consent for publication

Not applicable.

\section{Competing interests}

The authors declare that they have no competing interests.

Received: 25 March 2020 Revised: 17 April 2020

Accepted: 7 May 2020 Published online: 24 May 2020

\section{References}

1. Nichols J, Zevnik B, Anastassiadis K, Niwa H, Klewe-Nebenius D, Chambers I, Scholer $\mathrm{H}$, Smith A. Formation of pluripotent stem cells in the mammalian embryo depends on the POU transcription factor Oct4. Cell. 1998;95(3):379-91.

2. Takahashi K, Yamanaka S. Induction of pluripotent stem cells from mouse embryonic and adult fibroblast cultures by defined factors. Cell. 2006;126(4): 663-76.

3. Kim JB, Sebastiano V, Wu G, Arauzo-Bravo MJ, Sasse P, Gentile L, Ko K, Ruau $D$, Ehrich $M$, van den Boom D, et al. Oct4-induced pluripotency in adult neural stem cells. Cell. 2009;136(3):411-9. 
4. Lu R, Markowetz F, Unwin RD, Leek JT, Airoldi EM, MacArthur BD, Lachmann A, Rozov R, Ma'ayan A, Boyer LA, et al. Systems-level dynamic analyses of fate change in murine embryonic stem cells. Nature. 2009;462(7271):358-62.

5. Radzisheuskaya A, Chia Gle B, dos Santos RL, Theunissen TW, Castro LF, Nichols J, Silva JC. A defined Oct4 level governs cell state transitions of pluripotency entry and differentiation into all embryonic lineages. Nat Cell Biol. 2013;15(6):579-90.

6. Graham JM Jr, Edwards MJ, Edwards MJ. Teratogen update: gestational effects of maternal hyperthermia due to febrile illnesses and resultant patterns of defects in humans. Teratology. 1998;58(5):209-21.

7. Miyanari Y, Torres-Padilla ME. Control of ground-state pluripotency by allelic regulation of Nanog. Nature. 2012;483(7390):470-3.

8. Amano T, Nakamura K, Tani T, Kato Y, Tsunoda Y. Production of mice derived entirely from embryonic stem cells after injecting the cells into heat treated blastocysts. Theriogenology. 2000;53(7):1449-58.

9. Liou YC, Zhou XZ, Lu KP. Prolyl isomerase Pin1 as a molecular switch to determine the fate of phosphoproteins. Trends Biochem Sci. 2011;36(10): $501-14$

10. Nishi M, Akutsu H, Masui S, Kondo A, Nagashima Y, Kimura H, Perrem K, Shigeri Y, Toyoda M, Okayama A, et al. A distinct role for Pin1 in the induction and maintenance of pluripotency. J Biol Chem. 2011;286(13): 11593-603.

11. Lee TH, Chen CH, Suizu F, Huang P, Schiene-Fischer C, Daum S, Zhang YJ, Goate A, Chen RH, Zhou XZ, et al. Death-associated protein kinase 1 phosphorylates Pin1 and inhibits its prolyl isomerase activity and cellular function. Mol Cell. 2011;42(2):147-59.

12. Dewhirst MW, Vujaskovic Z, Jones E, Thrall D. Re-setting the biologic rationale for thermal therapy. Int J Hyperthermia. 2005;21 (8):779-90.

\section{Publisher's Note}

Springer Nature remains neutral with regard to jurisdictional claims in published maps and institutional affiliations.

Ready to submit your research? Choose BMC and benefit from:

- fast, convenient online submission

- thorough peer review by experienced researchers in your field

- rapid publication on acceptance

- support for research data, including large and complex data types

- gold Open Access which fosters wider collaboration and increased citations

- maximum visibility for your research: over $100 \mathrm{M}$ website views per year

At $\mathrm{BMC}$, research is always in progress.

Learn more biomedcentral.com/submissions 